\title{
Women in pediatric radiology
}

\author{
M. Ines Boechat
}

(C) The Author(s) 2010. This article is published with open access at Springerlink.com

\begin{abstract}
Women represent a significant proportion of pediatric radiologists in the United States, as shown on surveys by the American College of Radiology (ACR) and the Society for Pediatric Radiology (SPR). This review discusses the characteristics of this subgroup of specialists and issues uniquely related to them.
\end{abstract}

Keywords Women in medicine - Pediatric radiology · Practice of radiology

\section{Introduction}

Steady increased representation of women in medical schools has been reported by the American Association for Medical Colleges (AAMC), with the most notable changes occurring between 1970-71 and 1990-91 [1]. In those 20 years, the proportion of women graduates increased from $9 \%$ to $36 \%$, respectively. In 2008-09, women represented $48 \%$ of accepted medical school applicants, from $44 \%$ in 1998 , and $45 \%$ of the residents, from $36 \%$ in 1998 . The number of women residents is progressively increasing, whereas the number of men residents has been slowly declining since 2005 .

However, while the number of women residents continues to increase, there has been little change in the specialties dominated by women: Obstetrics and

Dr. Boechat has indicated that she has no relevant financial relationships or potential conflicts of interest related to the material presented.

M. I. Boechat $(\bowtie)$

Department of Radiological Sciences,

David Geffen School of Medicine at UCLA,

Los Angeles, CA 90095-1721, USA

e-mail: iboechat@mednet.ucla.edu
Gynecology (78\%), Pediatric (69\%), Medical Genetics $(66 \%)$ and Dermatology (61\%). In 2009, women represented $27 \%$ of practicing radiologists in the US. Their areas of specialization have the highest numbers in breast imaging (27\%), body imaging (9\%) and pediatric radiology $(6 \%)$. The unequal representation of women in medical specialties is not well explained and likely multifactorial, but underscores the need for understanding of gender-related issues in specialty choice. In view of the persistent shortage of pediatric radiologists in the US, it is worthwhile to study this particular subgroup of specialists and issues uniquely related to them, as the $6 \%$ of women that are pediatric radiologists represent $38 \%$ of the pediatric radiologists in the country.

The data sources include the ACR'S 2003 Survey of Radiologists, the American Association of Medical Colleges (AAMC) website plus data provided by the Society for Pediatric Radiology (SPR), and other professional societies, such as Society of Chairs of Academic Radiology Departments (SCARD), Society of Chairs of Radiology at Children's Hospitals (SCORCH) and Association of Medical School Pediatric Department Chairs (AMSPDC).

\section{ACR data}

In 2003, the American College of Radiology performed a survey of diagnostic radiologists, with a special focus on pediatric radiologists. Retrospective evaluation of the data collected generated papers on "A Portrait of Pediatric Radiologists in the United States" (2006) and "Women Radiologists in the United States" (2007) [2-4]. Information about women pediatric radiologists provided by these papers is summarized below. 
Several parameters can be used to define who is a pediatric radiologist; if the criterion used is that of individuals that spend $70 \%$ or more of their clinical time in pediatric radiology, then approximately $3 \%$ of radiologists, some 800-900 physicians, are pediatric radiologists. In 2003, 24\% of radiologists in training, including residents and fellows, and $18 \%$ of post-training, professionally active radiologists were women; of those, $6 \%$ were reported to be pediatric radiologists.

Within pediatric radiology, the proportion of women increased quite dramatically, as $30 \%$ or more of practicing physicians were women, versus $19 \%$ for other subspecialties and $15 \%$ for non-specialists [2].

Women also comprised a large number of those on a part-time position: more than $40 \%$ of pediatric radiologists that spend more than $30 \%$ of their time in the specialty were women, versus $20 \%$ or less in other specialties.

The authors of the 2003 report noted that the percentage of women in radiology was lower than the percentage of women in more traditional female specialties, such as internal medicine $(30 \%)$, pediatrics $(51 \%)$ and obstetrics-gynecology (39\%). However, women's subspecialty choices within diagnostic radiology approximately followed this profile, as the highest number of women was found within the field of breast imaging (27\%), followed by body imaging (9\%) and pediatric radiology $(6 \%)$ [2]. It was speculated whether the concentration of women in pediatric radiology would reflect gender role patterns, noting that factors such as lifestyle (call hours) and lack of interest for "high-tech" subspecialties, like interventional radiology and neuroradiology, may also play a role in their choice of subspecialty.

\section{SPR data}

Not all pediatric radiologists are members of the SPR; however, the organization congregates the majority of those working full time in pediatric radiology, mostly in academic centers, and many of those that work on a part-time basis and on community-based institutions, as reported on surveys done in 1998, 1999, 2002 and 2009.

Among information provided by Goske et al. [4] on the 1999 SPR member survey, was that the average age of its female members ( 45 years) was lower than that of the male members (49 years). In 2001, Forman et al. [5] reported that the younger half of the survey respondents were women, while the older half was constituted by males. Both authors found that the representation of women in the field was increasing rather than decreasing. SPR 2009 data shows an even higher proportion of women in pediatric radiology, up to $38 \%$. Both Table 1 and Fig. 1 depict the representation of
Table 1 SPR membership-increased participation of women

\begin{tabular}{lrcr}
\hline & \#Women & \%Women & Total \\
\hline 1958 & 2 & 5 & 39 \\
1969 & 16 & 10 & 156 \\
1979 & 50 & 16 & 310 \\
1989 & 147 & 21.5 & 686 \\
1999 & 330 & 31.5 & 1043 \\
2009 & 592 & 38 & 1556 \\
\hline
\end{tabular}

women within the SPR, from its foundation in 1958 to 2009 .

\section{Literature on determinants of specialty choice}

There is a recognized national shortage of pediatric radiologists. In the 2007-2008 update on employment market, pediatric radiology was found to be the third most difficult subspecialty in which to fill vacancies in academic centers, behind breast imaging and interventional radiology [6]. Reasons suggested include a financial disadvantage related to the lower practice revenues generated by pediatric radiologists, the lack of flexibility in a predominantly academic practice and the use of older imaging modalities $[2,6]$. A motive of concern is the fact that although there is an increasing number of women attending medical schools $(50 \%)$, the percentage of those choosing radiology $(25 \%)$ has not significantly changed over the past several years. Arnold et al. [6] attempted to address the issue of factors influencing subspecialty choice among radiology residents, with particular emphasis on pediatric radiology, in a 2008 questionnaire sent to radiology trainees in the US. Analysis of the responses showed the important criteria for trainees' decisions: area of strong personal interest, type of imaging modalities used in practice, intellectual challenge, strong personal knowledge, enjoyable rotations, marketability and

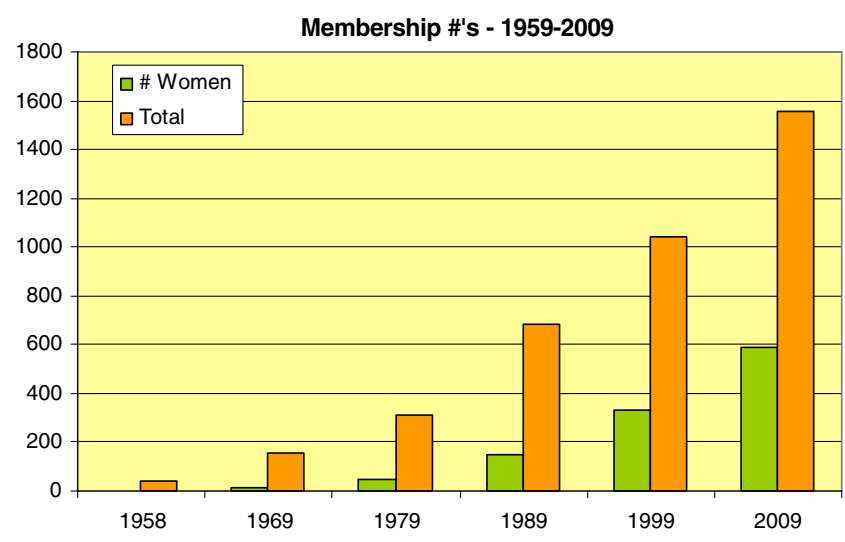

Fig. 1 SPR membership - male/female 
Table 2 Women in SPR leadership positions/recognition awards

\begin{tabular}{|c|c|c|c|c|c|c|}
\hline & Total & Men & $\%$ & Women & $\%$ & Found \\
\hline \multicolumn{7}{|l|}{ SPR } \\
\hline President & 52 & 44 & 88 & 8 & 12 & 1976 \\
\hline Gold Medal & 33 & 31 & 94 & 2 & 6 & 1996 \\
\hline Pioneer Award & 22 & 18 & 82 & 4 & 18 & 1998 \\
\hline Honorary Member & 58 & 52 & 90 & 6 & 10 & 1991 \\
\hline Singleton-Taybi Aw & 5 & 3 & 60 & 2 & 40 & 2006 \\
\hline \multicolumn{7}{|l|}{ REF/SPR } \\
\hline Young Invest Aw & 18 & 10 & 56 & 8 & 44 & 1993 \\
\hline J Haller T. Aw & 6 & 4 & 67 & 2 & 33 & 2007 \\
\hline T Griscom Educ Gr & 4 & 0 & 0 & 4 & 100 & 2002 \\
\hline Patriquin Aw & 7 & 4 & 57 & 3 & 43 & 2005 \\
\hline
\end{tabular}

job security. Another study by Robidoux et al. [7], measuring female medical students' level of interest in radiology, mentioned the importance of flexible hours, intellectual challenge, patient care and mentoring.

\section{Discussion}

The fact that the number of women pediatric radiologists is increasing suggests that one of the ways to decrease the workforce shortage is to make the field more attractive to female trainees, addressing issues of importance and concern to them. We should focus on the pipeline from medical school to the field of radiology, and later on pediatric radiology. The determinants of specialty choice during training mentioned above could be instruments used to attract women to the field. Although there are no data-specific outcomes regarding role models in pediatric radiology, it is likely that the visibility of women radiologists and improved mentoring might encourage women in the early stages of their careers to join the field.

The visibility of women within pediatric radiology has been steadily increasing over the years, particularly since the past decade. Table 2 depicts the representation of women within the leadership positions of the Society for Pediatric Radiology and recognition awards bestowed to its members. Although it is encouraging to see such an improvement in the visibility of women, underrepresentation persists. Table 3 is a 2009 snapshot of the representation of women among chairs of radiology

Table 3 Women in professional organizations - 2009

\begin{tabular}{lrrrrrr}
\hline & Total & Men & $\%$ & Women & $\%$ & Found \\
\hline SCARD & 164 & 151 & 92 & $13(2)^{\mathrm{a}}$ & 8 & 1993 \\
SCORCH & 67 & 51 & 86 & 16 & 24 & 1988 \\
AMSPPC & 142 & 120 & 84.5 & 22 & 14.5 & 1960 \\
\hline
\end{tabular}

${ }^{a}$ Thirteen women members, two are pediatric radiologists departments (SCARD), pediatric radiology departments $(\mathrm{SCORCH})$ and the organization of department chairs in pediatrics (AMSPDC). The relatively high representation within SCORCH (24\%) better resembles the representation within departments of pediatrics $(14 \%)$ than in general diagnostic radiology $(8 \%)$. Again, it is possible that gender-related issues and larger numbers of women in such areas play a role in the increased representation of women in leadership positions in pediatric radiology and pediatrics rather than in diagnostic radiology.

Mentoring efforts for women in radiology have been a long-term goal of the American Association for Women in Radiology (AAWR), which has a strong representation of pediatric radiologists, both as members and leaders. The organization emphasizes networking, the development of good leadership skills and guidelines for women's issues, such as maternity leave and child-care provisions, as three methods to support women in the field [8]. The values promoted in the AAWR serve as a model for gender-related policies in pediatric radiology departments across the nation.

\section{Conclusion}

A limitation of this review is that the most recent comprehensive ACR data is from 2003, stressing the need for more current and continuous evaluation of gender representation in radiology.

It is worthwhile to reflect on the topics raised by this review, in order to better understand gender-related issues in the choice of specialty and to work towards possible solutions to the current shortage of specialists in the field of pediatric radiology, recognizing the role played by the increasing number of women who choose it as a career.

Acknowledgements Carol Rumack, MD, FACR, ACR President in 2009, provided valuable comments and support. 
Jennifer Boylan, SPR executive director, assembled data from the SPR and ACR files.

Lise Thorsby, SCARD account executive, provided data on women chairs.

Open Access This article is distributed under the terms of the Creative Commons Attribution Noncommercial License, which permits any noncommercial use, distribution, and reproduction in any medium, provided the original author(s) and source are credited.

\section{References}

1. Leadley J (2009) Women in U.S. academic medicine: statistics and benchmarking report 2008-2009. AAMC
2. Leuris RS, Ghargavan M, Sunshine JH (2007) Women radiologists in the Unites States: results from the American College of Radiology 2003 survey. Radiology 242:802-810

3. Merewitz L, Sunshine JH (2006) A portrait of pediatric radiologists in the United States. AJR 186:12-22

4. Goske MJ, Lebowitz RL, Lieber M et al. (2000) Pediatric radiologists: who we are and what we do. Pediatr Radiol 30:581-586

5. Forman HP, Traugici J, Corey AM et al. (2001) Pediatric radiology at the millennium. Radiology 220:109-114

6. Arnold RW, Goske MJ, Bulas DI et al. (2009) Factors influencing subspecialty choice among radiology residents: a case study of pediatric radiology. J Am Coll Radiol 6:635-642

7. Robidoux MA, Packer MM, Applegate KE et al. (2009) Female medical students' interest in radiology careers. J Am Coll Radiol 6:246-253

8. American Association for Women Radiologists (1998) Member Network: Articles related to career and personal issues for women in medicine and radiology. http://www.aawr.org. Accessed 28 Dec 2009 